\title{
Tuo Shan Yan Dam and City Ningbo: Exploring the Historical Logic of Urban Water Management through a Big City of China
}

\author{
Xiao Yun Zheng ${ }^{1}$ and Shen Ji Min ${ }^{2}$ \\ 1. Yunnan Academy of Social Sciences, Kunming City 650024, China \\ 2. Ningbo City Research Association for Water Culture, Ningbo City 315016, China
}

\begin{abstract}
Tuo Shan Yan Dam is a small dam which was built above Yinjiang River at the Yinjiang Town, Ningbo City, Zhejiang Province of China in 833 AD, but it is greatly contributed to Ningbo City, a current big port city of China. The dam and the matched system had become a key hydro-infrastructure to the city's existence and development, and irrigation of the countryside nearby the city from ninth century up to 1987, a big dam was built at upper reach to control water of the river. Tuo Shan Yan Dam functioned an important role in the local water management and met a series of purposes perfectly, mainly as: (a) regulation of the river water; (b) save the flood; (c) stop the salinization; (d) urban water supply; (e) storage of flesh water; (f) irrigation; (g) ship transportation. And it is a miracle that it has been functioned for more than one thousand years. This dam also influenced the local social life and people's spiritual world simultaneously. The construction of the dam and its matched hydro-system is in line with the Chinese ancient logic of urban water management to manage river to meet a multi-proposes of urban development by a key project and a systemic engineering design. It is an important case for better understanding of ancient Chinese urban water management and to learn from the history for current water sustainability. Accordingly, the dam's design, construction and its influence on the local societies are studied in this article.
\end{abstract}

Key words: Tuo Shan Yan Dam, construction, historical logic water management, urban development, Ningbo City, China.

\section{Introduction}

Being situated at the midpiece of Chinese coastline and the south wing of Yangtze River delta, Ningbo City is an influential historical and commercial city in Zhejiang Province of China, with population of 7.85 million $^{1}$. Currently, it is one of the most important port cities and the commercial centers of the Yangtze River delta south wing, it keeps the position of the largest port of the world from $2008^{2}$. It is also the east estuary

Corresponding author: Xiao Yun Zheng, professor, research fields: water history, rural water management, water and cultural diversity.

1 Statistical Bulletin of the National Economic and social Development of Ningbo City 2015. http://www.tjcn.org/tjgb/201604/32666_4.html (accessed on 12 December 2016).

${ }^{2} \mathrm{Yu}$ Yong Jing. Ningbo keeps the position of the largest port of the world for 8 years continually. Ningbo daily. 20 Dec. 2016. p. 1. of the Jinghan Canal ${ }^{3}$ to the sea, accordingly it is the main place of the east of China which links to the ocean. With a long history, the early residence in this area was dating back to 7,000 years ago according the archeological discovery near Ningbo City, named Hemudu Culture, one of the earliest human residences which is discovered in China so far. It was under the local administrations in different periods in the history but current site of the city was begun in $812 \mathrm{AD}$, the Tang Dynasty, the capital of Min Prefecture was moved to current site that begin its urban history until today for more than 1,000 years.

China is a river based country in history to shaping

\footnotetext{
3 Jinghan Canal is the longest canal in China also in world, with length of $1,797 \mathrm{~km}$, crosses a geographical area from Ningbo city in east of China to Beijing in the north of China. As a historic influential canal, it was listed into the UNESCO WORLD HERITAGE in 2014.
} 
the rural residence, city and agriculture, industry, transportation, etc., accordingly in the early age of the Chinese urban development, the major rivers nearby places were strongly considered as the site for building the city, especially rivers like Yellow River basin and Yangtze River basin. However, all the influential ancient cities in China were built close to the major rivers. Being situated near rivers, the city had convenient water supply and irrigation system, which later also made transportation convenient. Ancient Chinese water urban water management was strongly focused on the water systemic design logically depended on the river to construct its urban hydro-network ${ }^{4}$. Ningbo City is a case in point to meet the features above. In $812 \mathrm{AD}$, current site was selected as the place to build the new city of the local prefecture government, based on the site where the meet place of the three rivers is located, such as $\mathrm{Yu}$ Yao Jiang River, Feng Hua Jiang River and Yong Jiang River, of which these rivers, Yu Yao Jiang River, and Feng Hua Jiang River are originated from the mountains then meet together and become Yong Jiang River which flows into the East Sea. But after the new city was built, water was not enough for urban supply in spring, autumn and winter, the dry seasons due to rapid population growth. In addition, the salinization strongly troubled the city due to sea water which flows backward into the inland around $30 \mathrm{~km}$, there are no cultivation and drinking along the basin after the salty sea water flows backward. Therefore, how to increase the urban water supply and stop the salty disaster becomes an urgent business to the local government. Subsequently, Tuo Shan Yan Dam was built to meet these purposes in $833 \mathrm{AD}$ by the local county government, Mao county. After the dam and its matched system were built, water supply was increased effectively in same time the salty disaster

\footnotetext{
${ }^{4}$ Xiaoyun Zheng. The ancient urban water system construction of China:

the lessons from history for a sustainable future. Int. J. Global Environmental Issues.

Vol. 14, Nos. 3/4. 2015, pp. 187-199.
}

was reduced, irrigation for the agriculture in surrounding of the city was also increased simultaneously. This situation had become a key fact that it supported the urban development for more than one thousand years. This paper aims to discover the construction of Tuo Shan Yan Dam and its logic of design systemically which played a key role in development of Ningbo City in 11th century, and for better understanding of the historical water management in China, especially how to manage the urban water based on the rivers. Therefore, the logic of water management, construction of the dam and its matched system, its social influences up to today will be discussed in this paper.

\section{The Logic of the Water Management from 11th Century}

Mentioned above, the meet place of the three rivers was selected to build the new city of the Min prefecture's capital in $812 \mathrm{AD}$. After the new city was built, rapid population growth and economic development by the sea trade brought shortage of urban water supply by the fact that water supply was mainly relying on Feng Hua Jiang River. At same time, the disaster of salinization by sea water flows backward was deteriorated in this situation, usually it could flow backward for $3 \mathrm{~km}$ above of the Tuo Shan Yan Dam site. Therefore how to increase urban water supply and improve the agricultural irrigation in surrounding countryside have become an urgent business to the local governments. A series of projects were considered but the Yin Jiang River, the main tributary of Feng Hua Jiang River management was strongly considered to be the key project.

Yin Jiang River, a main tributary of Feng Hua Jiang River, was originated from Si Ming Shan mountain, with length of $69.4 \mathrm{~km}$ and width of 100-130 m before Tuo Shan Yan Dam and 90-100 m after Tuo Shan Yan Dam. Along with the river, there are many small tributaries flowing into it. As the source of a series of rivers, Si Ming Shan mountain has large range and 
high sea level one in the local, the peaks with sea level of 750-900 $\mathrm{m}^{5}$. Rainfall is concentrated seasonally in summer, and it is a fact that Yin Jiang River is a short river and it receives water from many tributaries on the way, and the altitude difference, caused often huge flooding along the basin, this situation also brought often disaster to the local residences, local people were suffering in this situation for long before Tuo Shan Yan Dam was built. For increasing the urban water supply and reducing the flood risk, the local government decided to build a dam on the waterway of Yin Jiang River.

The proposal of building Tuo Shan Yan Dam was proposed by the governor of Mao County of the local, Mr. Wang Yuan Wei. After times of investigation, he proposed to build a dam at the mouth of the Tuo Shan valley of the Yin Jiang River that starts the river's reach to the flat basin. The reasons to select this place for building the dam are: (a) here is the narrow place between the valley and flat basin that is easy for construction; (b) it is possible to stop water by the dam and elevate water level of the river then lead it into other waterway for water supply to the flat basin; (c) it was possible to stop seawater flows backward into the valley area then to save the salinization disaster; (d) it can regulate water seasonally.

The proposed logic of building the dam and matched system is: the dam stops water and elevates water level of the river in Yin Jiang River in the dry season then diverts water into Nan Tang River which links with the Yin Jiang River and locates at upper dam for hundreds miters. Based this propose, 70\% of river water will flow in Yin Jiang River and 30\% flows into Nan Tang River in the rainy season, but in counter 70\% flows into Nan Tang River and 30\% flows into Yin Jiang River in the dry season. Therefore the river water was regulated seasonally for increasing urban water supply and irrigation in the countryside and reducing the river flood risk.

${ }^{5}$ The Editing Committee. Yong Jiang River Book. Zhonghua Book Bureau, Beijing, 2000. p. 48.
After the dam was built, $70 \%$ of the Yin Jiang River water was diverted into the Nan Tang River in the dry seasons due the elevated water level by the dam, then water led into two sub-rivers. Water from Nan Tang River flows into the city from the South Gate, then gets and stores in Lake Ye, Lake Ri, and the urban rivers. It was remarkable that not just water supply of the city was increased effectively by this project, but it also performs to store fresh water in the lakes and urban rivers for regulation of the water supply seasonally. This change increased the capacity of urban development and supported the city for subsequent more than one thousand years. Other river led water to west flat area of Yin Jiang River, accordingly irrigation was improved effectively in this area and it promoted the agricultural development nearby, it was also supported urban development.

In the rainy season, $70 \%$ water crosses the dam and continues flowing in the river and 30\% flows into the draining river Nan Tang River. But considering the capacity of drainage in this river, three floodgates were built that severed to regulate water seasonally, draining more water from Nan Tang River into other rivers in rainy season.

After Tuo Shan Yan Dam was built, a hydro-system based on it was built for drainage, urban water supply, water storage, irrigation, stop sand, ship transportation, etc, in thereafter year.

In 1255, three floodgates were built at Nan Tang River where the eastern Yin Jiang town is located, the link place of the canal between Yin Jiang River and Nan Tang River to increase drainage of Nan Tang River to Yin Jiang River (see No. 3 at Fig. 1). It means part of water flows from Yin Jiang River to Nan Tang River will be drained into Yin Jiang River to reduce flood risk in Nan Tang River and to the city in rainy season. But in the dry season, floodgate will be closed to keep water in Nan Tang River. After times of rebuilding until 1924, this dam was built as a stone dam with length of $320 \mathrm{~m}$.

In 1524, a dyke called Guang Tang was built on the 

Management through a Big City of China

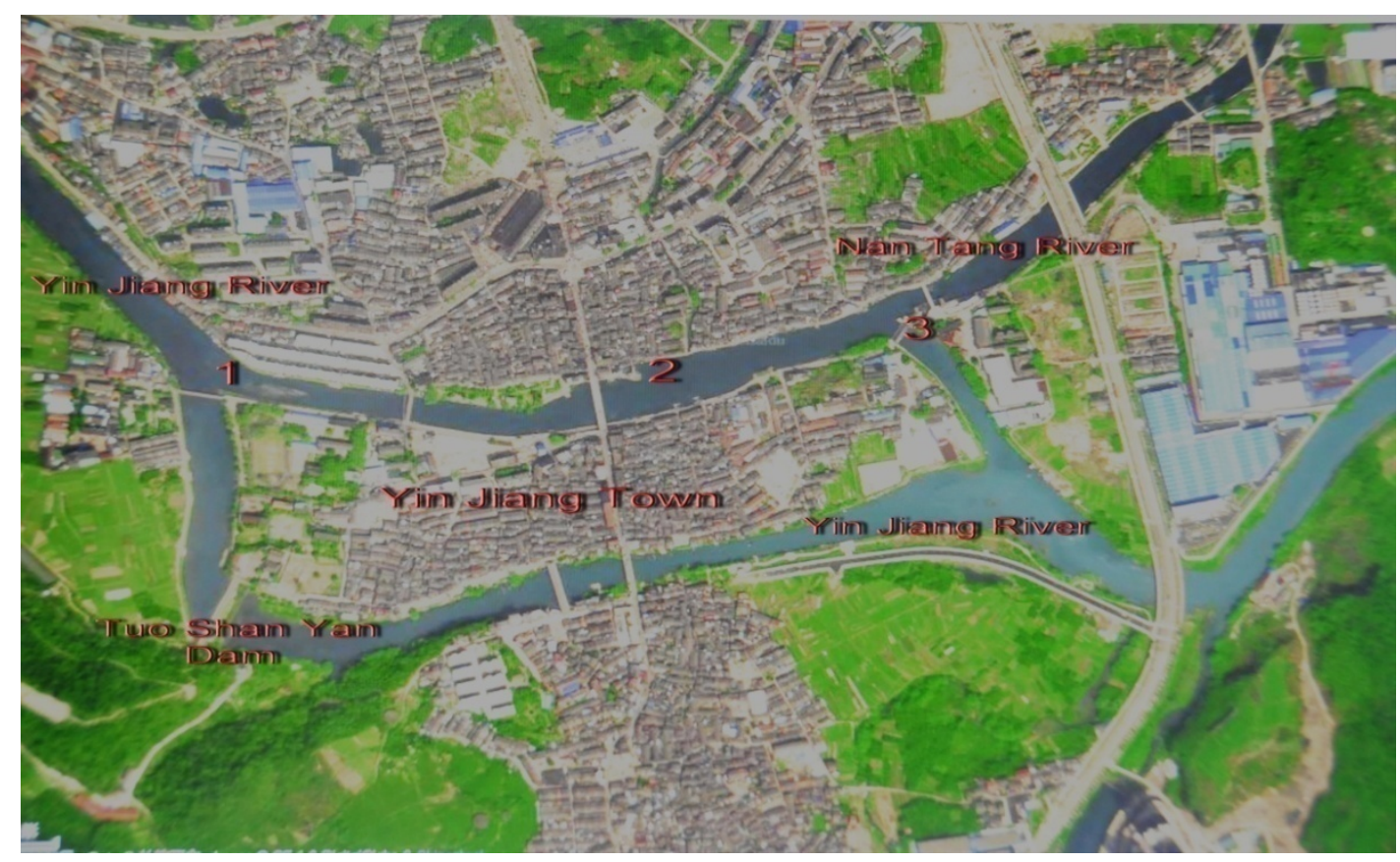

Fig. 1 The sketch map of the dam and rivers nearby ${ }^{6}$.

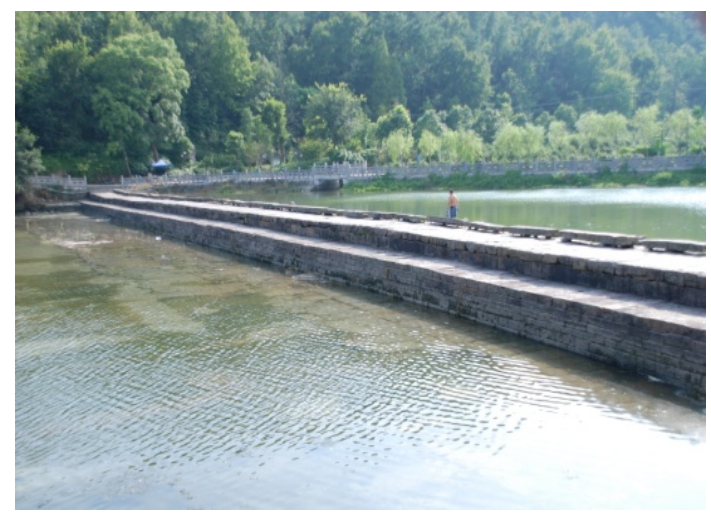

Fig. 2 (a) Tuo Shan Yan Dam in different angle;

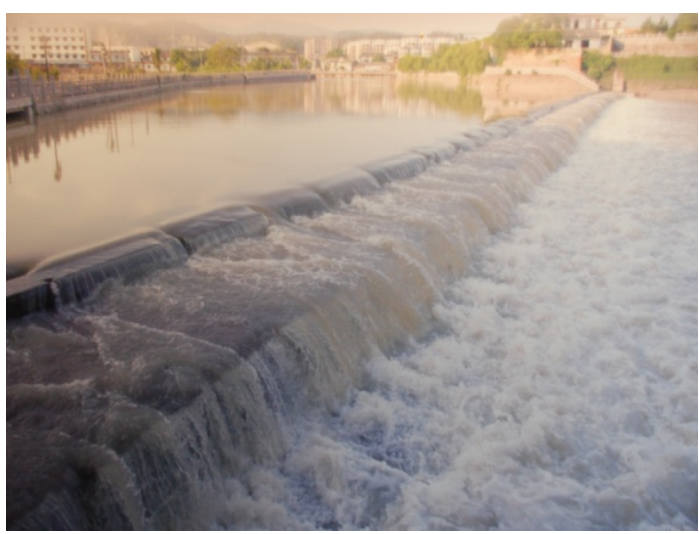

Fig. 3 (a) The dam during the raining season;

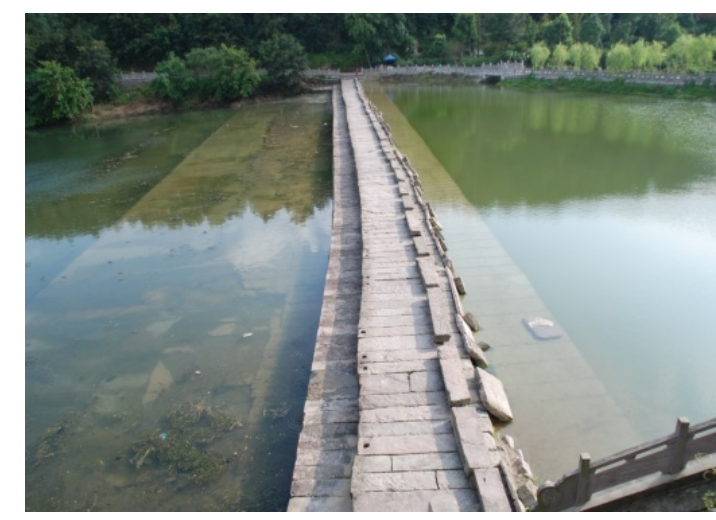

(b) Tuo Shan Yan Dam in different angle ${ }^{7}$.

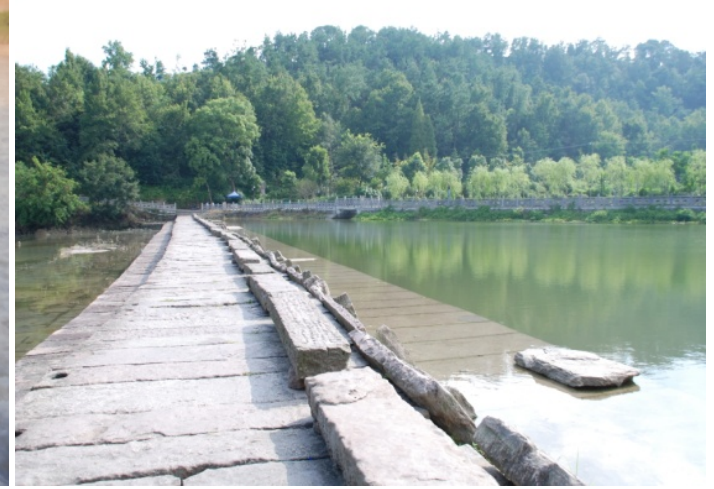

(b) The dam during the dry season ${ }^{8}$.

\footnotetext{
${ }^{6}$ Figure 1 with permission of Xiao Yun Zheng.

${ }^{7}$ Figure 2 with permission of Xiao Yun Zheng.

${ }^{8}$ Figure 3 with permission of Xiao Yun Zheng.
} 


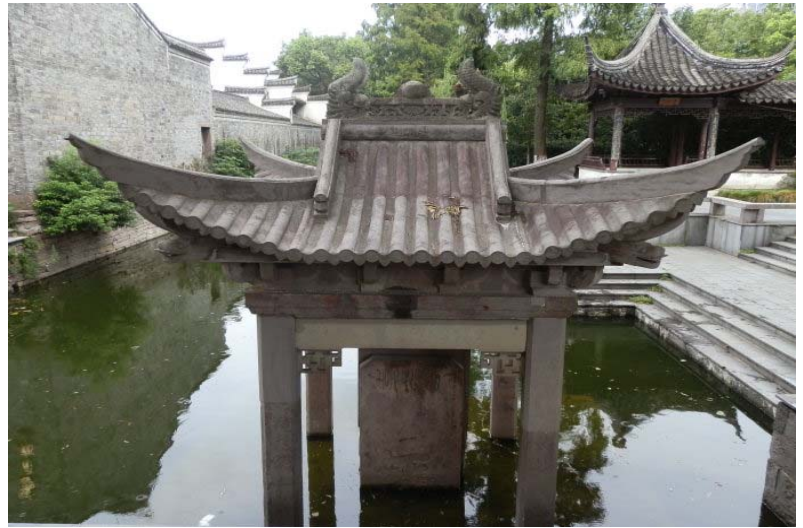

Fig. 4 Stone tablet of water-level at Ningbo City ${ }^{9}$.

Nan Tang River where is just about 500 m close Tuo Shan Yan Dam (see No. 2 at Fig. 1). This dyke starts from north Yin Jiang town stretch across the river then ends at place near the bank about $15 \mathrm{~m}$ to form a bay, therefore proposal of building this dyke was to increase water level for water supply to residences of the north bank and ship transportation in the dry season, but during the rainy season, water can cross the dyke into the river.

After the water was introduced from Yin Jiang into Ningbo city, it was flowed into the Lake Ye, Lake Ri and urban rivers, finally it was led to Yong River from the east gate of the city after it was cycled in the urban water system, this situation was in line with the ancient logic of Chinese urban water management. But seasonally, the water yields from the rivers were different, therefore urban water balance becomes a key project for water security. How to solve this problem for the ancient people was to use floodgates in the urban water system to regulate the water level for storing water and drainage. Thus a stone tablet of water-level was built inside the city for measuring the water level in the urban water system so as to regulate the water by the floodgates. The example shown at Fig. 4 was built during 1253 1258 (Song Dynasty) and continued rebuilding in thereafter dynasties. After this facility was built, the urban water system was severed perfectly to the urban water regulation to keep water

\footnotetext{
${ }^{9}$ Figure 4 with permission of Xiao Yun Zheng.
}

in the dry season and drainage in the rainy season.

Anyway, Tuo Shan Yan Dam and its matched facilities constructed a hydro-system to Ningbo City and the neighbouring areas, functioning in urban water supply, irrigation, stop salinization, storage of fresh water, ship transportation, etc., from ninth century, of which the functions, the most important one is water supply and stopping the salinization disaster to the city, it brought possibility to the urban existence and development based on the fact that dated back to around two hundred years before the dam was built, there is no a stable circumstance to develop a capital city of the local prefecture due to flood, water shortage and salinization. A document written in 1147 described the importance of Tuo Shan Yan Dam as:

Tuo Shan Yan Dam is bearing in a heaviness, thousands hectare of the farmland are no trouble to be irrigated perfectly in the seven distracts of the countryside, and it store water to be the lakes and flows smoothly into the river to coping the trouble of drought and flood, all of it is benefited from Tuo Shan Yan Dam.

After the dam was constructed, the river and draining river are divided, the saline water is not come again but fresh water flows into loughs fully. It flows into the urban area and rounding around the villages, the paddy fields of the seven distracts are all irrigated rely on the dam ${ }^{10}$.

Accordingly, it could be saying absolutely, Tuo Shan Yan Dam and its hydro-system had functioned a key role to the city's existence from ninth century up to 1987, a large dam and its reservoir called Jiao Kou Dam, was built at upper Yin Jiang River main riverway, it controlled flood and function in water supply of the city.

\section{The Aspect of the Dam's Engineering}

What is worth to be noted to Tuo Shan Yan Dam is

\footnotetext{
${ }^{10}$ Wui Jian. Siming Tuo Shan Yan Dam Water Management Book. The Record of the Riverway of Zhejiang and Explaining in Map. China Water \& Power Press. 2014. Beijing. p. 74.
} 
that it is the first flagstone structure dam recorded and found in China so far. It is not just remarkable in its systemic logical design to build a hydro-system depending on the dam but also its engineering achievement creatively in that time.

With length of $113.6 \mathrm{~m}$, altitude of $3.05 \mathrm{~m}$ and width of $3.5 \mathrm{~m}$, it was built with flagstone and big wooden pillars. The first record of its structure was in 1242 by Wui Jian as:

The dam was covered by flagstone, but it likes a house that inside of it is empty and supports by big wooden pillars. While the river in flooding, it is filled in sand to protecting the dam but it will be moved after water returned ${ }^{11}$.

According to the legend, the first stage of construction of the dam was to put some big wooden pillars into the river to stop water because it is impossible to construct the dam by stones directly as a result of riptide. There are ten workers who died during the wooden pillars were put into the river. Thus after water was stopped by the pillars, flagstones are able to be used to build the body of the dam above the pillars.

It is a fact that the structure of the dam's main body is not known well so far. According to the historical record, the dam was built on the big wooden pillars which lie on the bottom of the river, above the pillars, the main body was built with 36 storey flagstones. So its altitude was debated for long and described in the publications from $4 \mathrm{~m}$ to $27 \mathrm{~m}$ differently. In 1995, a scientific test shows that the centre of the dam is 3.85 $\mathrm{m}$ of altitude, and both ends are $2 \mathrm{~m}$, it is arched dam benefits to against sink. According to this research, the bottom of the dam's foundation was built with interlayer of clay and dinas which are 3.7-6.4 m of altitude above the river's conglomerate bottom. Above the foundation, the dam body was built with flagstones ${ }^{12}$. The dam was built with three steps, the

\footnotetext{
${ }^{11}$ Wui Jian. Siming Tuo Shan Yan Dam Water Management Book. The Record of the Riverway of Zhejiang and Explaining in Map. China Water \& Power Press. 2014. Beijing. p. 74.

12 Shen Zhi Lan and Chen Wan Feng. More about the mystery of Tashan Weir in Tang Dynasty. Science and Technology Review. No. 11, 1995. Beijing. p. 19.
}

first step is bottom which was covered with flagstones with width of $8-15 \mathrm{~m}$. The second step is made altitude above the first step $1.2 \mathrm{~m}$ and width of $1.63 \mathrm{~m}$, and third step is made altitude above second step 0.75 $\mathrm{m}$. There are 152 flagstones used to build this dam with length of 2-3.3 m, width of 0.5-1.6 m and thickness of $0.2-0.35 \mathrm{~m}^{13}$. The structure is shown at Fig. $5^{14}$.

Another remarkable hydro-technology in this area in the ancient time is the floodgate. The water supply from the rivers in Ningbo and neighbouring areas is strongly featured in seasonal difference, therefore seasonal water balance was also important for the local water management. Accordingly, floodgate was used popularly to meet this propose. Depended on this technique, water was regulated in rivers, lakes and urban water system effectively. It closes and opens based on the water situation. Floodgate also performs the functions of stopping sand and sea water flow backward into the urban rivers, etc. According to the historical record, after the dam was built, three floodgates were built at the places where distance to the dam was $7.5 \mathrm{~km}, 9 \mathrm{~km}$ and $22.5 \mathrm{~km}$, to regulate water depended on the seasonal water level, during the rainy season, the floodgates will be open for drainage but during the dry season, the floodgates will be closed to keep water for urban supply ${ }^{15}$. But unfortunately, these floodgates were destroyed on the history. Fig. 6 shows the gate-pillar of a floodgate relic at upper Tuo Shan Yan Dam (see No. 1 at Fig. 1) to stop sand and regulate river water which was built in 1242, it was closed and opened by planks and hand operated depending on water level. There are some scales at the gate-pillar to measure the water level.

\footnotetext{
${ }^{13}$ Yan Yan et al. The Riverway's Water Culture: Ningbo of Zhejiang. Printed by The Center for Research and Education of Water Culture. 2012. p. 37.

${ }^{14}$ The original map from Chen Shi. A walk to Tuo Shan Yan Dam. Impressions of Yinjiang. Ningbo News. No. 18. 2014. Ningbo.

${ }^{15}$ Shen Zhi Lang. The Miracle of Ancient Chinese Water Conservancy: The Famous Tashan Weir Constructed in Tang Dynasty. Science and Technology Review. No. 4, 1992. pp. 48-51.
} 


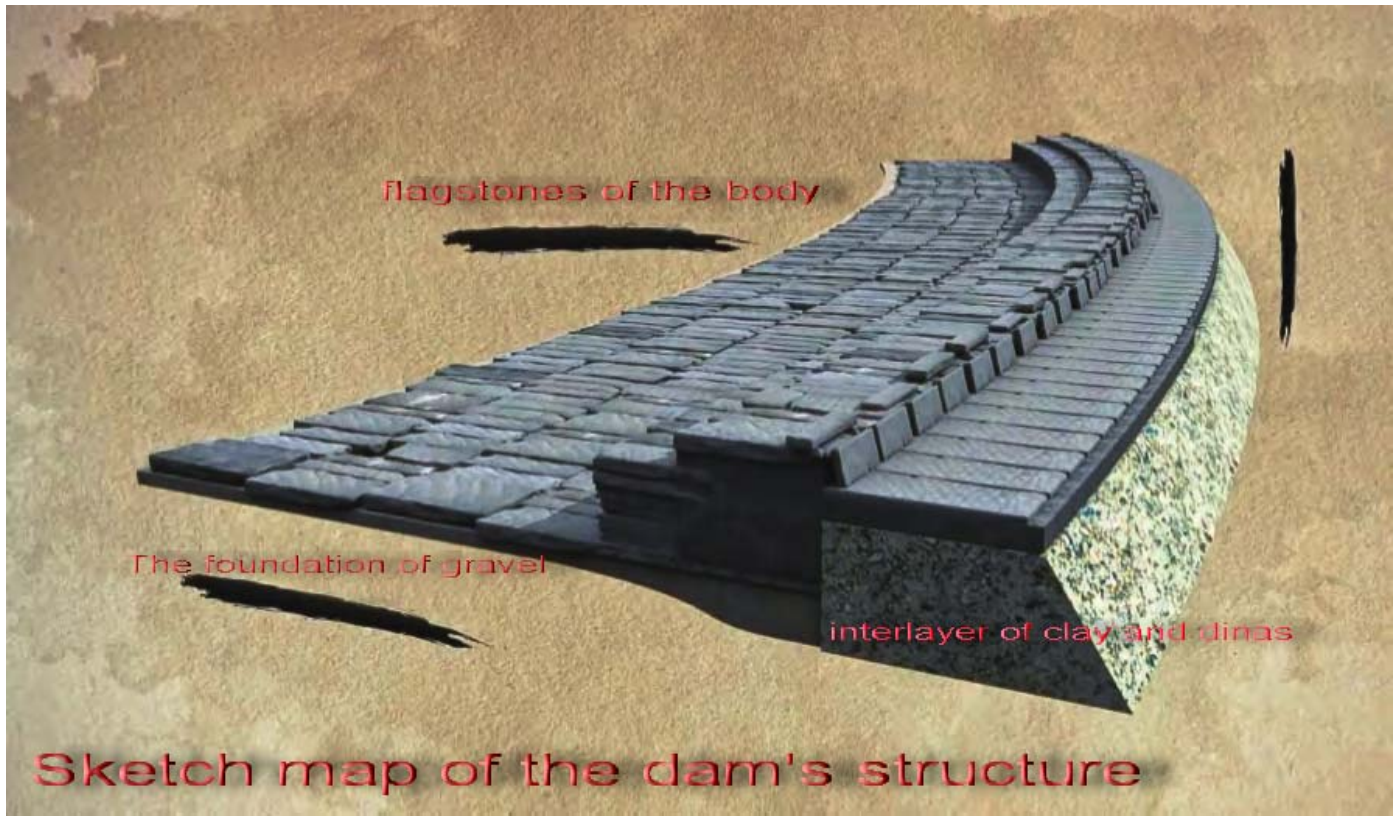

Fig. 5 The sketch of Tuo Shan Yan Dam's structure.

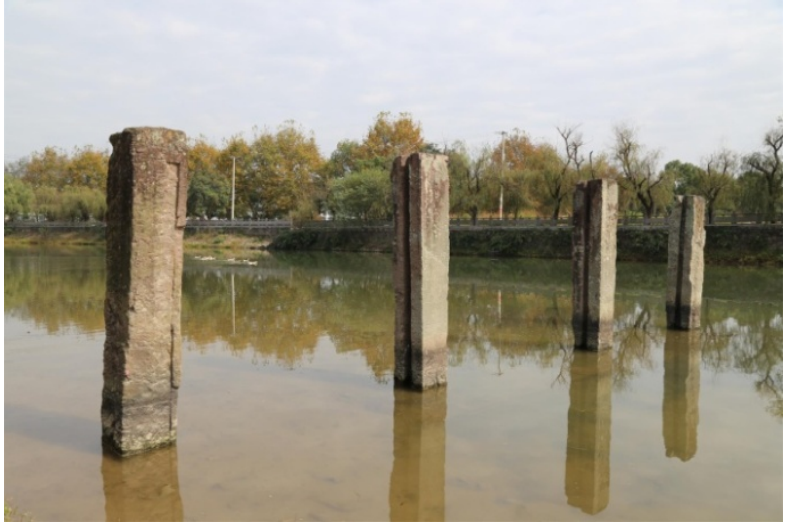

Fig. 6 The relic of stone pillars of the floodgate ${ }^{16}$.

Anyway, these are reflected in advanced urban hydro-technique at that time ${ }^{17}$.

\section{The Influences of the Social Aspect}

It is greatly worth to note that Tuo Shan Yan Dam is not just a stone structural construction, but also deeply influenced the local people's spiritual world and social life by its great achievements.

After the dam was built, the local people were saved from saliniztion disaster and the agricultural productivity was increased effectively by

\footnotetext{
${ }^{16}$ With permission of Wang Wei Nan.

${ }^{17}$ The Editing Committee. Yong Jaing River Book. Zhonghua Book Bureau, Beijing, 2000. p. 48.
}

improvement of the irrigation. Some towns were formed along the rivers, for example, the Yinjiang Town beside the dam is a famous one. But most important is the improvement of water supply to Ningbo City that brings a stable circumstance for the city's long development. All of these was embedded in the local spiritual world and practiced in the real life by the ways of memory, gratefulness and worshipping the builders of the dam for one thousand years.

According to the historical record, the dam was built organized by the governor of the local county, Mr. Wang Yuan Wei. In 831, during his birthday dinner, he stated the proposal of building a dam to solve the troubles of water. Then he paid very hard works for this project for two years, the construction of the dam was finished in 833, and troubles of flood, water shortage and saliniztion disaster were solved obviously in a short time. Consequently, local people celebrate the construction and show their gratefulness to the governor Wang and ten young men who paid their life for the construction in aftertime every year.

On 3rd March, 6th June and 10th October of Chinese calendar every year, the local people take three time celebration to the dam, it had become fairs until today. The fair is mainly used to worship the 
former governor Wang and other dead people because they have become the gods ideally in the local in subsequent years, of which governor Wang Yuan Wei was understood as the water god to control the local water and bless local people to have a good situation of water. Local people also built a temple to worship them beside the dam, and after times rebuilding it is a large one today. The temple includes two main buildings, the main building is for worshipping governor Wang Yuan Wei and another smaller one is for worshipping ten young men and other people who greatly contributed to the dam and water management. During the temple fairs, thousands people from the local and neighboring areas gathered together at Yin Jiang town where the dam's location to worship the gods, take part in fair market, enjoy performances, foods, recreation, etc. But among the activities, most important one is the parade carrying the statues of the gods including governor Wang and other ten young men as well as pray in the temple to the gods' statues. There are many rituals that will be taken during the fairs simultaneously.

After the governor Wang was recognized as the water god by the local people, this phenomenon has influenced a broad areas in the east Zhejiang province. There are more than 30 temples which were named Tuo Shan temple in east Zhejiang province to worship governor Wang $^{18}$. The temple is a place not just to bless the luck and show gratefulness but also for educating people to learn from Mr. Wang how to be a good person.

Anyway, it is few to find a case like Tuo Shan Faire in China that the people keep their memory to their heroes of water management through rituals in the real life and the memory becomes their religious faith integrallty for more than one thousand years. What is important to the water management is that this ritualistic religious memory has been functioned perfectly to keep and enhance the ideal of

${ }^{18}$ Li Guang Zi. Tua Shan Fair and its Faith. The Journal of Shangqiu Occupational Technologies College. No. 3, 2011. pp. 72-73.
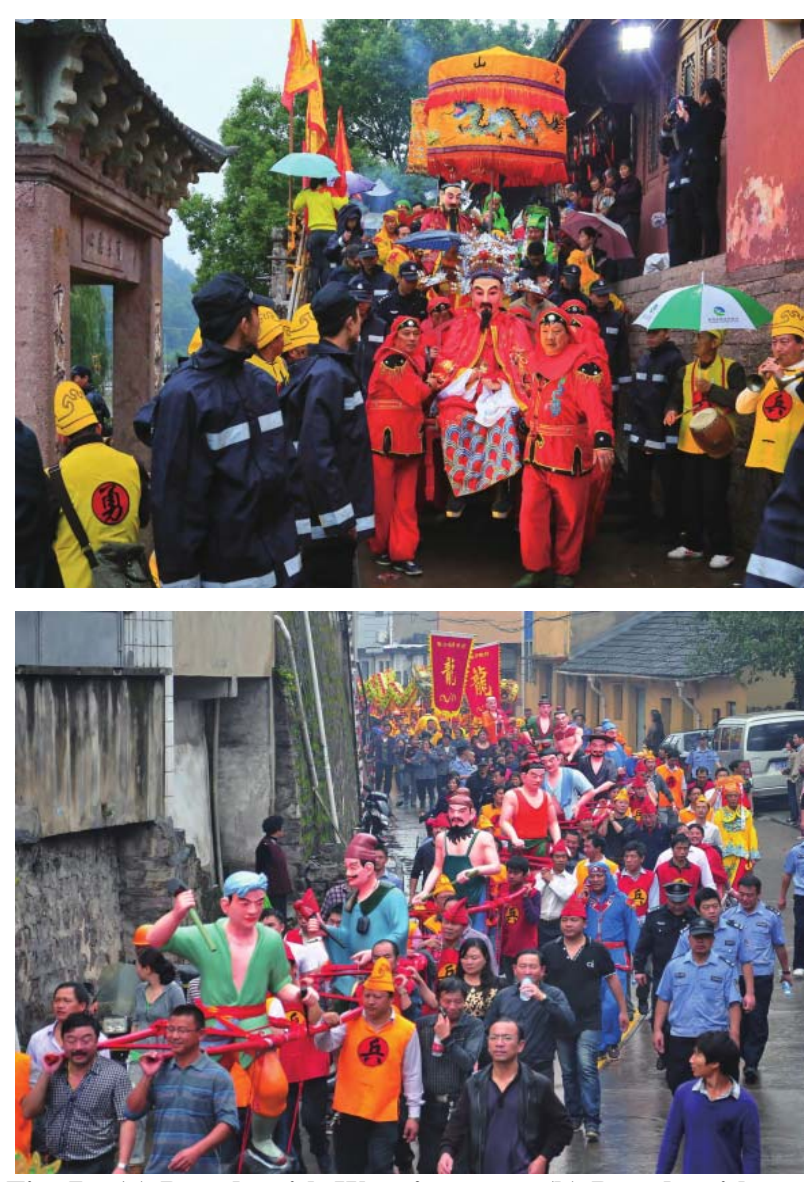

Fig. 7 (a) Parade with Wang's statue; (b) Parade with ten man's statues ${ }^{19}$.

water management, and encourage people to management water continually generation after generation. Therefore, this memory has become the cultural foundation of the sustainable water management and subsistence.

Consequently, Tuo Shan Yan Dam was appointed as The National Important Relic Protecting Site of China in 1988. In 2015, it was appointed as ICID register of heritage structures by International Commission on Irrigation and Drainage. These are greatly benefited to the dam's protection and sustainability.

\section{Conclusion}

Tuo Shan Yan Dam is a small dam but it is in line with historical logic of water management of Chinese to manage river to meet the demands of urban water

\footnotetext{
19 Originality photos at a walk to Tuo Shan Yan Dam. Impressions of Yinjiang. Ningbo News. No. 18. 2014. Ningbo.
} 
supply, drainage, defense, extension, transportation, etc. The ancient Chinese are wise to design a hydro-system depended on a key river project just like Tuo Shan Yan Dam. It is not difficult to find similar cases in China, for example, Song Hua Ba Dam in Kunming City ${ }^{20}$. The key project and systemic design are two important features of ancient water management, it also reflected their wisdom in that time. Therefore, as a small dam, Tuo Shan Yan Dam functioned an important role in the local water management and meets a series of purposes perfectly, mainly as: (a) regulation of the river water; (b) save the flood; (c) stop the salinization; (d) urban water supply; (e) storage of flesh water; (f) irrigation; (g) ship transportation. And it is a miracle that it has been functioned for more than one thousand years. This dam also greatly contributed to the local development especially the urban development of Ningbo City, which becomes a fact that the city was developed relied on this dam as key infrastructure before 1950s. It also influenced the local social life and folk religious faith, created a cultural phenomenon depended on the dam and it performed an important role in the local water management simultaneously.

Anyway, how to find what are the key project and logical design for water management is still important for a sustainable urban water management in present urbanization, it is also valuable to learn from the history.

\footnotetext{
${ }^{20}$ Xiao Yun Zheng. Water management in a city of southwest China before the 17th century. Water Science \& Technology: Water Supply |13.3| 2013. pp. 574-581.
} 